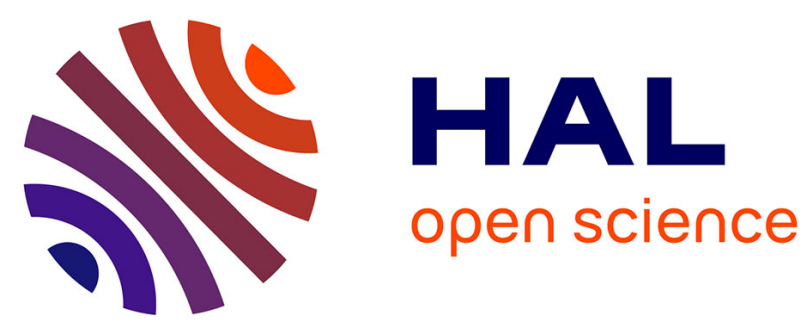

\title{
La Revue forestière a dix ans
}

René Rol

\section{- To cite this version:}

René Rol. La Revue forestière a dix ans. 1959, pp.257-257. 10.4267/2042/27491 • hal-03381997

\section{HAL Id: hal-03381997 \\ https://hal.science/hal-03381997}

Submitted on 18 Oct 2021

HAL is a multi-disciplinary open access archive for the deposit and dissemination of scientific research documents, whether they are published or not. The documents may come from teaching and research institutions in France or abroad, or from public or private research centers.
L'archive ouverte pluridisciplinaire HAL, est destinée au dépôt et à la diffusion de documents scientifiques de niveau recherche, publiés ou non, émanant des établissements d'enseignement et de recherche français ou étrangers, des laboratoires publics ou privés. 


\section{REVUE FORESTIERE FRANÇAISE \\ 1959 \\ AvR1I, \\ $\mathrm{N}^{\circ} 4$}

Dans ce numéro: $P$. BEnda: La propagandei en matière forestière. - $P$. Allouard: L'évolution de la consommation des papiers et cartons et ses répercussions sur l'économie forestière française. - J. GoBERT: Réserves artistiquẹs et réserve de silence en Chartreuse. $\longrightarrow$ G. Roure: Tourisme de la nature vivante en Côte d'Ivoire. - J. Guinaudeau: Une expérience d'emploi d'engrais dans un reboisement par semis de pin maritime à Mimizan (Landes).

\section{LA REVUE FORESTIĒRE A DIX ANS}

En décembre 1948, la Revue des Eaux et Forêts paraissait pour la dernière fois et $M$. le Directeur Oudin considérant que " dans un pays comme la France où depuis bien des siècles la technique forestière a fait l'objet de travaux considérables, la publication d'une revue forestière apparaissait à tous comme absolument nécessaire ) accepta que l'Ecole Nationale des Eaux et Forêts prenne en charge l'édition d'une nouvelle publication : " LA REvUE Forestière FranÇAISE »).

M. le Conservateur des Eaux et Forêts Léon Sciraeffer, Professeur d'Economie forestière à l'Ecole, qui consacrait déjà à la Revue des Eaux et Forêts une part importante de son activité, devint Rédacteur en Chef do la Revue forestière française, sauvant ainsi une forme de publication qui datait de 1842 . Le premier numéro paraissait en avril I949, il y a exactement Io ans.

Dans l'esprit de son Directeur, cette Revue devait être "l'expression vivante du travail collectif de tous ceux qui, à un titre quelconque, s'intéressent à la forêt française ». Léon ScHAEFFER sut en faire un organe vivant qui acquit rapidement en France et à l'étranger, une réputation incontestée, témoignant de l'activité de nos techniciens et de la valeur des doctrines forestières françaises.

Mais Léon SCHAEFFER disparaissait brutalement le I2 mars 1953 et la direction de la Revue fut confiée à un Comité de Rédaction constitué par M. l'Ingénieur Principal des Eaux et Forêts Fourchy, assisté de MM. les Ingénieurs Boutin et BouvareL, puis lorsque, en 1954, $M$. Fourchy quitta la Station de Recherches, M. le Conservateur R. VINEY, qui avait déjà remplacé $M$. SchaEFfer comme Professeur d'Economie forestière, accepta de prendre également la Direction de la Revue. Il est actuellement aidé dans cette tâche très lourde par MM. les Ingénieurs Bouvarel et PARdÉ.

La Direction de la Revue avait promis à ses lecteurs de publier, chaque année, dix numéros d'une cinquantaine de pages, et ces nu- 
méros devaient comporter un exposé des doctrines et des travaux forestiers français et une large synthèse des travaux et ouvrages étrangers, ceci sans aucun parti pris de doctrines d'écoles, officielles ou autres.

Il ne nous appartient pas de dire si ces engagements ont été tenus, nos Lecteurs peuvent en juger. Mais nous devons préciser qu'en dix ans, la Revue Forestière Française a publié 8680 pages. au lieu des 5000 promises, contenant 639 articles, et 20 numéros spéciaux ayant trait à des questions d'actualité.

Ajoutons qu'elle a paru très régulièrement grâce à la compréhension et à la diligence dont a fait preuve notre Maître Imprimeur, M. THomas, auquel il convient de rendre un hommage particulièrement mérité.

Le Comité de Rédaction a été encouragé à persister dans la voie qu'il s'était tracée par la progression du nombre des abonnements. Parti d'environ 500 en I949, ce nombre a maintenant franchi le cap des 2000 et 450 numéros sont envoy's chaque mois à l'étranger.

Le prix de l'abonnement a dî suivre, évidemment, l'évolution du coût de la vie, mais avec un décalage appréciable; fixé à $500 F$ en I949, il a dî̀ être porté récemment à I $500 \mathrm{~F}$, les Préposés des Eaux et Forêts bénéficiant d'un tarif réduit à $75^{\circ} \mathrm{F}$. Il est juste d'ajouter que cos prix exceptionnellement bas ne peuvent être maintenus que grâce à une importante subvention du. Fonds Forestier National accordée dans le but do permettre une large diffusion des techniques forestières modernes.

On peut cependant déplorer que dans un pays où la forêt couvre actuellement plus de II millions d'hectares, le nombre de lecteurs do la Revuc soit encore aussi faible!

La direction d'une revue technique qui veut atteindre un public très varié est chose délicate, dont le Comité de Rédaction s'acquitte à la satisfaction de tous. Pour atteindre le but cherché, une collaboration aussi étroite que possible est indispensable entre le Comité de Rédaction et les Lecteurs. Souhaitons que cette collaboration, dont nous nous plaisons à constater l'existence, s'amplifie encore. Que nos Lecteurs nous apportent leur concours, mais aussi qu'ils nous adressent leurs suggestions et ne nous ménagent pas leurs critiques. Il en sera largement tenu compte. C'est à cette condition que notre Revue deviendra encore plus vivante et plu,s attrayante.

Nancy, ${ }^{\text {er }}$ avril 1959.

R. Rol. 